\title{
The socio-economic determinants of infant mortality in Nepal: analysis of Nepal Demographic Health Survey, 2011
}

\author{
Khim Bahadur Khadka ${ }^{1 *}$, Leslie Sue Lieberman ${ }^{2}$, Vincentas Giedraitis ${ }^{3}$, Laxmi Bhatta ${ }^{4}$ and Ganesh Pandey ${ }^{1}$
}

\begin{abstract}
Background: Infant mortality reflects not only the health of infants but societal well-being as a whole. This study explores distal socioeconomic and related proximate determinants of infant mortality and provides evidence for designing targeted interventions.

Methods: Survival information on 5391 live born infants (2006-2010) was examined from the nationally representative Nepal Demographic Health Survey 2011. Bivariate logistic regression and multivariate hierarchical logistic regression approaches were performed to analyze the distal-socioeconomic and related proximate determinants of infant mortality.

Results: Socio-economic distal determinants are important predictors for infant mortality. For example, in reference to infants of the richest class, the adjusted odds ratio of infant mortality was 1.66 (95 \% Cl: 1.00-2.74) in middle class and 1.87 (95\% Cl: 1.14-3.08) in poorer class, respectively. Similarly, the populations of the Mountain ecological region had a higher odds ratio ( $\mathrm{aOR}=1.39,95 \% \mathrm{Cl}$ : 0.90-2.16) of experiencing infant mortality compared with the populations of the Terai plain region. Likewise, the population of Far-western development region had a higher adjusted odds ratio ( $\mathrm{aOR}=1.62,95 \% \mathrm{Cl}: 1.02-2.57$ ) of experiencing infant mortality than the Western development region. Moreover, the association of proximate determinants with infant mortality was statistically significant. For example, in reference to size at birth, adjusted odds ratio of infant dying was higher for infants whose birth size, as reported by mothers, was very small (aOR $=3.41,95 \% \mathrm{Cl}: 2.16-5.38)$ than whose birth size was average. Similarly, fourth or higher birth rank infants with a short preceding birth interval (less than or equal to 2 years) were at greater risk of dying (aOR $=1.74,95 \% \mathrm{Cl}$ : 1.16-2.62) compared to the second or third rank infants with longer birth intervals. A short birth interval of the second or the third rank infants also increased the odds of infant death ( $\mathrm{aOR}=2.03,95 \% \mathrm{Cl}: 1.23-3.35)$.

Conclusions: Socioeconomic distal and proximate determinants are associated with infant mortality in Nepal. Infant mortality was higher in the poor and middle classes than the wealthier classes. Population of Mountain ecological region and Far western development region had high risk of infant mortality. Similarly, infant dying was higher for infants whose birth size, as reported by mothers, was very small and who has higher birth rank and short preceding birth interval. This study uniquely addresses both broader socioeconomic distal and proximate determinants side by side at the individual, household and community levels. For this, both comprehensive, long-term, equity-based public health interventions and immediate infant care programs are recommended.
\end{abstract}

Keywords: Socioeconomic factors, Proximate determinants, Infant mortality, Nepal

\footnotetext{
*Correspondence: khadka_16@hotmail.com

'Save the Children, Kathmandu, Nepal

Full list of author information is available at the end of the article
} 


\section{Background}

Infant mortality rate is defined as the risk of a live-born child to die before its first birthday. Infant mortality rates reflect economic and social conditions for the health of mothers and newborns, as well as the effectiveness of health systems [1]. The causes of infant mortality are strongly correlated to structural factors, like economic development, general living conditions, social wellbeing, and the quality of the environment, that affect the health of entire populations [2]. In industrial world, a dominant factor in the decline in infant mortality has been social and economic progress [3]. Therefore, in a scenario where the infant mortality rate is declining, the social, economic or demographic determinants assume important roles. In Nepal demographic variables, previous birth interval and survival of the preceding child predominated as determinants of infant mortality, particularly in rural areas of Nepal [4].

Millennium Development Goal 4 aims for a twothirds reduction in infant mortality by the year 2015 [5]. In Nepal it is declined by $42 \%$ over the last 15 years and is on track to achieve Millennium Development Goal 4 [6]. Infant mortality was 46 per 1000 live births during the period 2006-2010 [7]. However, not all segments of the society equally benefited from the progress that was made and many impoverished people in Nepal are struggling with poor health care [8]. Regional and district inequity observed in the budget allocations have contributed to inequitable health outcomes [9]. Similarly, there is a huge rural to urban disparity reflected in the physician to population ratio of 1:850 in capital city Kathmandu and 1:30,000 outside of the capital [10]. According to the Mosley-Chen framework, socioeconomic factors at the community, household or individual levels operate through five proximate determinants and are the pathways through which socioeconomic processes affect infant health [11]. Therefore, this study aims to explore the role of distal socioeconomic and related proximate determinants of infant mortality at different levels in Nepal.

\section{Methods}

\section{Data sources}

This study analyzed the secondary data from the nationally representative Nepal Demographic Health Survey (NDHS), 2011 accessed from the Measure Evaluation Demography Health Survey 2011 Nepal [12]. The Enumeration Area (EA) was defined as a ward in the rural areas and a subward in the urban areas. In Nepal, Village Development Committees (VDCs) are considered as rural and Municipalities as urban area. There are nine wards in a VDC, and the number of wards ranges from nine to 35 in municipalities. Stratification was achieved by separating each of the 13 domains into urban and rural areas. The number of wards and sub-wards in each of the 13 domains were not allocated proportional to their populations due to the need to provide estimates with acceptable levels of statistical precision for each domain; and for the urban and rural domains of the country as a whole. The vast majority of the population in Nepal resides in the rural areas. In order to provide for national urban estimates, urban areas of the country were over sampled. In each stratum, samples were selected independently through a two-stage selection process. In the first stage, EAs were selected using a probability proportional-to-size strategy. In order to achieve the target sample size in each domain, the ratio of urban EAs over rural EAs in each domain was roughly 1 to 2, resulting in 95 urban and 194 rural EAs (289 EAs). Due to the non-proportional allocation of the sample to the different domains and to over sampling of the urban area in each domain, sampling weights are considered to ensure the actual representativeness of the sample at the national level as well as the domain levels.

\section{Conceptual framework}

The Mosley and Chen conceptual framework for the study of child survival in developing countries (Fig. 1) [11] was adapted based on the available information in the 2006-2010 NDHS datasets. Table 1 gives the selection and classification of variables used in this study in view of the conceptual framework.

\section{Key explanatory variables}

The outcome was infant death, which is the death of a live born infant in the first year of life. In this analysis, it was re-coded as a binary variable. The explanatory variables included community level distal socioeconomic, the household and individual level socioeconomic determinants and proximate determinants, covering maternal, infant, pre-natal, delivery, and post-natal factors in line with conceptual framework of study.

\section{Community level socioeconomic determinants}

People living in municipalities including towns and the capital city were considered as urban people and people living in villages or rural areas were considered as rural people. Development regions covered five administrative regions while ecological regions covered Mountain, Hill and Terai ecological zones.

\section{The household and individual level socioeconomic determinants}

In this study, the main socioeconomic determinant is household wealth quintile (index). It is a method developed by the ORC Macro to measure the socioeconomic level for a household in a ranked order. It uses principal-component analysis based on respondents' household assets, amenities, and services [13]. In the 2011 NDHS, this variable covered information on 


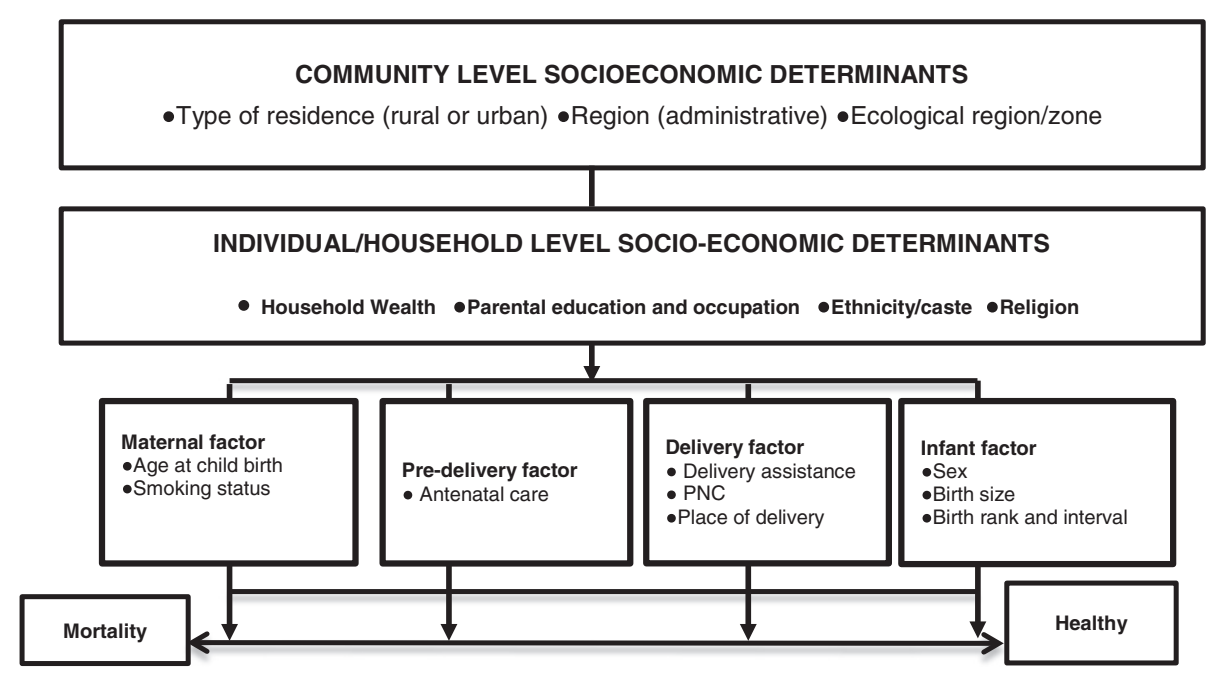

Fig. 1 Conceptual framework of determinants influencing infant mortality

material possessions (e.g., television, bicycle car), as well as dwelling characteristics such as source of water, sanitation facilities and type of material used in flooring [13]. The individual's rank is based on their household score and divided into quintiles where the first quintile is the poorest $20 \%$ of the households and fifth quintile is the wealthiest $20 \%$ of the households [14]. Similarly, categorical or ordinal variables; no formal school education, primary education, secondary education and higher education are used for mother's and father's education level. The other variables consist of sex of the child, ethnicity and religion of mother. Ethnic/caste groups with similar characteristics are categorized. Religion of the mother is categorized into two categories: Hindu and others (Buddhist, Christian, Kirat, and Muslim). Age of mother, while giving childbirth is categorized into two groups (less than 20 and 20 year to 35 years of age).

\section{The intermediate or proximate determinants}

The proximate determinants include birth size, birth order and previous birth interval. Size at birth (very small, small, average size, large or very large) was obtained by asking mothers. Birth rank was categorized into three groups: first, 2-3 birth rank and $4^{+}$-birth rank. The preceding birth interval was grouped into two groups: less than 2-year and two or more years. These two variables are combined into one variable with categories [15]. First rank, 2-4 birth rank with 2-years or more of preceding spacing, 2-3 birth rank with less than 2-years of preceding spacing, $4^{\text {th }}$ or more birth order with 2-year or more of preceding spacing and $4^{+}$birth rank with less than 2 -years of preceding spacing.

\section{Data analysis}

A synthetic cohort life table approach was used to calculate infant mortality rate. Data were weighted by sampling probabilities to represent the structure of Nepali population using weighting factors provided with the NDHS [16]. Due to incomplete exposure for death, births in the month of interview were excluded from the analysis.

Frequency tabulations were used to describe the data, followed by the bivariate analysis using Chi-square tests and contingency table analyses to examine the association of all potential determinants on infant mortality without adjusting for other covariates. Prior to multivariate hierarchical logistic regression analysis, multi-collinearity between the variables was assessed and variables with multi-collinearity were not considered for the analysis. For example, parental education level and occupation were highly correlated with wealth index, so these variables were not considered in the analysis though they were significant. In addition, only those variables that were significant in the bivariate analysis were further analyzed using multivariate hierarchical logistic regression. A p-value less than 0.05 was considered as significant and odds ratios at 95 per cent confidence intervals were determined.

Based on a conceptual framework describing the hierarchical relationships between different groups of variables, multivariate hierarchical logistic regression was used to assess the association of distal socioeconomic and proximate determinants on infant mortality after controlling other variables. In this approach the associations of more distal variables can be examined without improper adjustment by proximate or intermediate variables that may be mediators of the effects of more distal variables [16]. At the initial stage, community level variables were entered in the model and only those that were significantly associated with infant mortality were retained in the first model. In the second stage, the socioeconomic level variables were added to the first 
Table 1 Operational definition, categorization and dummy coding of the variables

\begin{tabular}{|c|c|}
\hline Variables/ Determinants & Definition and categorization \\
\hline \multicolumn{2}{|l|}{ COMMUNITY LEVEL } \\
\hline Ecological region & Ecological zone $(1=$ Mountain, $2=$ Hill and $3=$ Terai $($ plain area/Lowlands $))$ \\
\hline Region (administrative) & Developmental regions ( $1=$ Far western, $2=$ Mid western, $3=$ Eastern, $4=$ Central and $5=$ Western) \\
\hline Residence & Type of residence ( $0=$ Rural, $1=$ Urban) \\
\hline \multicolumn{2}{|l|}{ HOUSEHOLD LEVEL } \\
\hline Household wealth index & Composite index of household amenities ( $1=$ Poorest, $2=$ Poorer, $3=$ Middle, $4=$ Richer and $5=$ Richest) \\
\hline Maternal ethnicity/caste & Maternal ethnicity/caste ( 1 = Dalit, $2=$ Janajati, 3 = Others, $4=$ Brahmin, Chettri and Newar $)$ \\
\hline Maternal religion & Maternal religion ( $1=$ Hindu, 2 = Buddhist, Muslim, Christian and Kirat) \\
\hline Maternal education & $\begin{array}{l}\text { Maternal formal years of schooling ( } 0=\text { No formal school education, } 1=\text { Primary education ie up to class five, } 2=\text { Secondary } \\
\text { and higher education ie above class five) }\end{array}$ \\
\hline Father's education & $\begin{array}{l}\text { Paternal formal years of schooling }(0=\text { No formal school education, } 1=\text { Primary education ie up to class five, } 2=\text { Secondary } \\
\text { and higher education ie above class five) }\end{array}$ \\
\hline Mother's occupation & $\begin{array}{l}\text { Mother's occupational status ( } 0=\text { Not working, } 1=\text { Official (professional, technical, managerial and clerical), } 2=\text { Sales and } \\
\text { services, } 3=\text { Skilled manual, } 4=\text { Unskilled manual and } 5=\text { Agriculture) }\end{array}$ \\
\hline Father's occupation & $\begin{array}{l}\text { Father's occupational status ( } 1=\text { Official (professional, technical, managerial and clerical), } 2=\text { Sales and services, } 3= \\
\text { Skilled manual, } 4=\text { Unskilled manual and } 5=\text { Agriculture) }\end{array}$ \\
\hline \multicolumn{2}{|l|}{ PROXIMATE LEVEL } \\
\hline Sex of infant & Sex of infant ( $0=$ Male and $1=$ Female) \\
\hline Birth size & $\begin{array}{l}\text { Subjective assessment of the respondent on the birth size }(1=\text { Very large, } 2=\text { Larger than average; } 3=\text { Smaller than } \\
\text { average, } 4=\text { Very small and } 5=\text { Average })\end{array}$ \\
\hline $\begin{array}{l}\text { Birth rank and birth } \\
\text { interval }\end{array}$ & $\begin{array}{l}\text { Birth rank and birth interval of baby }\left(1=1 \text { st birth rank, } 2=2 \text { nd or } 3 \text { rd birth rank and birth interval } \leq 2 \text { years; } 3=\geq 4^{\text {th }}\right. \\
\text { birth rank and birth interval }>2 \text { years, } 4=\geq 4 \text { th birth rank, birth interval } \leq 2 \text { years; } 5=2 \text { nd or } 3 \text { rd birth rank and birth } \\
\text { interval }>2 \text { years) }\end{array}$ \\
\hline $\begin{array}{l}\text { Age of mother at child } \\
\text { birth }\end{array}$ & Maternal age at child birth ( $1=<20$ years, $2=20$ to 35 years of age) \\
\hline Antenatal care visit & Antenatal service received by the mother $((0=$ No and $1=$ Yes, any visit $)$ \\
\hline Use of tobacco & Use tobacco by mother $(0=$ No, smokes nothing and $1=$ Yes but did not cover the frequency and duration of smoking) \\
\hline Place of delivery & Place of delivery $(0=$ Home and $1=$ Health facility $)$ \\
\hline Delivery assistance & $\begin{array}{l}\text { Birth attendance during delivery }(0=\text { By Traditional Birth Attendant/other and } 1=\text { By Skill Birth Attendant or health } \\
\text { professional) }\end{array}$ \\
\hline $\begin{array}{l}\text { Post Natal Check up } \\
\text { (PNC) visits }\end{array}$ & Postnatal check up visits ( $0=$ No, $1=$ Within $24 \mathrm{~h}$ and $2=1$ day to 45 days $)$ \\
\hline \multicolumn{2}{|l|}{ OUTCOME LEVEL } \\
\hline Death of infant & Death of infant $(0=$ No and $1=$ Yes $)$ \\
\hline
\end{tabular}

model, and only the significant variables were retained to assess the association of the socioeconomic level variables in the presence of community level variables. In the last stage, the proximate determinants were entered into the second model, and the associations of the significant proximate determinants were assessed in the presence of both socioeconomic and community level variables. Negelkerke pseudo $\mathrm{R}^{2}$ was used to assess goodness-of-fit of logistic models. The Statistical Package for Social Science (SPSS 16.0 for Windows) software was used to analyze the data.

The Nepal DHS 2011 was approved by the ethics review board of the ICF Macro International and the Ministry of Health and Population. All respondents were verbally informed before consenting to their participation. This research study ensured that their participation was voluntary and independent when answering and interacting with the interviewers. The researcher also maintained confidentiality of the information, which was received after permission from Measure DHS.

\section{Results}

This research included 5391 live-births, occurring within the 5 years preceding the survey. The characteristics of explanatory variables are given in Table 2. The most infants $(53 \%)$ were from the Terai ecological region while only $8 \%$ of the infants were from the Mountain ecological region. Around $32 \%$ of infants were from the Central development region whereas $11 \%$ of infants were from the Far-western development region. A 
majority (91\%) of infants were from rural areas. About $26 \%$ of the infants were from the poorest household, compared to about $14 \%$ of infants from the richest household. The majority (66\%) of infants were average in size at birth. About $6 \%$ of infants were born with a $>=4$ birth rank \& a birth interval of $=<2$ years.

Infant mortality rate was found to be 46 per 1000 live births between 2006 and 2010. IMR was 44 deaths per 1000 live births in the Terai ecological region, compared to 65 deaths per 1000 live births in the Mountain region. It was highest in the Far-western development region (66 deaths per 1000 live births) and lowest in the Western development region (40 deaths per 1000 live births). Similarly, IMR was higher (47 deaths per 1000 live births) in rural areas than in urban areas (40 deaths per 1000 live births). The IMR was 55 in the middle class households compared to 29 in the wealthiest households. IMR was 138, as compared with 38 in larger than average birth size. However, rest of the categories had no significant differences in infant mortality with average size at birth. IMR was 72 in $2-3$ birth rank $\&=<2$ years of birth interval and 81 in $>=4$ birth rank $\&=<2$ years of birth interval category.

Table 2 also shows the crude odds ratios of the explanatory variables associated with infant mortality. This study found a wide variation in the odds of infant death by ecological zone and administrative developmental regions. The higher unadjusted odds of infant death was found in mountain ecological region $(\mathrm{uOR}=1.45,95 \%$ CI: 1.04-2.03) with reference to Terai ecological region. Similarly, there was higher unadjusted odds of infant death in Far western development region $(\mathrm{uOR}=1.74$, $95 \%$ CI: 1.11-2.71) with reference to Western development region. Likewise, in reference to infants of the Richest class, the unadjusted odds ratio of infants dying of Richer $(\mathrm{uOR}=1.90,95 \% \mathrm{CI}$ : 1.07-3.38), Middle $(\mathrm{uOR}=2.11,95 \% \mathrm{CI}: 1.21-3.67)$, Poorer $(\mathrm{uOR}=2.21$, $95 \%$ CI: $1.28-3.80)$ and Poorest class (uOR $=2.53,95 \%$ CI: 1.51-4.21) was increased, respectively. In reference to average sized babies at birth, unadjusted odds ratio of infant dying was higher for infants whose birth size according to the mother was very small ( $\mathrm{uOR}=3.22,95 \%$ CI: 2.11-4.92). Similarly, the unadjusted odds ratio of infant mortality for fourth or higher birth rank infants with a short preceding birth interval (less than or equal to 2 years) was high ( $\mathrm{uOR}=2.37,95 \% \mathrm{CI}$ : $1.46-3.85$ ) compared to the second or third rank infants with longer birth intervals. A short birth interval of the second or the third rank infants also showed an increased odd of infant deaths ( $\mathrm{uOR}=2.07,95 \% \mathrm{CI}: 1.37-3.12)$.

Compared to infants born to mothers who have no formal education or are illiterate, the unadjusted odds of dying was higher for infants whose mothers have secondary and higher levels of formal education $(\mathrm{uOR}=1.55$, 95 \% CI: 1.15-2.10). Similarly, compared to infants born to fathers who have no formal education or are illiterate, the unadjusted odds of dying was higher for these infants compared to those whose fathers have secondary and higher levels of formal education ( $\mathrm{uOR}=1.71,95 \% \mathrm{CI}$ : 1.26-2.32). However, parental education level variables were not entered into the model simultaneously as they were found to be highly correlated to the wealth index (Table 2).

In the first model of multivariate hierarchical logistic regression, community level socio-economic determinants had associations with infant mortality. The Mountain ecological region had a higher adjusted odds ratio (aOR $=1.39,95 \%$ CI: $0.90-2.16$ ) of experiencing infant mortality compared with the Terai plain/low land region. Similarly, the Far-western development region had a higher adjusted odds ratio ( $\mathrm{aOR}=1.62,95 \% \mathrm{CI}: 1.02-2.57$ ) of experiencing infant mortality than with reference to the Western development region.

The second model presents the results after adding the wealth index as a socioeconomic determinant of infant mortality. Even after inclusion of this variable in model 2, the association of community level determinants with infant mortality was retained for example, the adjusted odds ratio of infant death was 1.33 in mountain ecological region with reference to the Terai ecological region. Similarly, the adjusted odds ratio of infant death was 1.58 in the Far western development region with reference to the Western development region. Furthermore, in reference to infants of the Richest class, the adjusted odds ratio of infant dying was 1.66 (95 \% CI: 1.00-2.74) in Middle class and 1.87 (95 \% CI: 1.14-3.08) in Poorer class respectively.

The third model presents the results after adding all the proximate determinants. The reduction of the significance level of socioeconomic determinants (wealth index) after inclusion of the proximate determinants (i.e. size of the baby at birth and birth rank and birth interval) indicates that distal determinants are important predictors for infant mortality. For example, in reference to infants of the Richest class, the adjusted odds ratio of infant dying increased to 1.72 (95 \% CI: 1.03-2.87) in Middle class and 1.95 (95 \% CI: 1.18-3.24) in Poorer class, respectively. Similarly, the association of proximate determinants with infant mortality was statistically significant. In reference to average sized babies, adjusted odds ratio of infant dying was higher for infants whose birth size according to the mother was very small $(\mathrm{aOR}=3.41,95 \% \mathrm{CI}: 2.16-5.38)$. Similarly, the adjusted odds ratio of infant mortality for fourth or higher birth rank infants with a short preceding birth interval (less than or equal to 2 years) was higher (aOR $=1.74,95 \%$ CI: $1.16-2.62)$ compared to the second or third rank infants with longer birth intervals. A short birth interval of the second or the third rank infants also showed increased odds of infant deaths $(\mathrm{aOR}=2.03,95 \%$ CI: 1.23-3.35) (Table 3). 
Table 2 Infant mortality rate (per 1000 live births), 5 year periods preceding the survey and unadjusted Odds Ratio by explanatory variables $(n=5391$, weighted)

\begin{tabular}{|c|c|c|c|c|c|c|}
\hline \multirow[t]{2}{*}{ Determinants } & \multirow{2}{*}{$\begin{array}{l}n, \\
\text { weighted }\end{array}$} & \multirow[t]{2}{*}{ Percent } & \multirow[t]{2}{*}{ IMR [95 \% Cl] } & \multicolumn{3}{|c|}{ Bivariate logistic regression } \\
\hline & & & & $\mathrm{UOR}$ & $95 \%$ & \\
\hline \multicolumn{7}{|l|}{ Ecological Region } \\
\hline Mountain & 428 & 7.9 & 65 [49-80] & $1.45^{*}$ & 1.04 & 2.03 \\
\hline Hill & 2131 & 39.5 & $45[35-55]$ & 1.12 & 0.84 & 1.50 \\
\hline Terai & 2833 & 52.5 & $44[34-55]$ & 1 & - & - \\
\hline \multicolumn{7}{|l|}{ Development Region } \\
\hline Far western & 605 & 11.2 & 66 [49-83] & $1.74^{*}$ & 1.11 & 2.71 \\
\hline Mid western & 793 & 14.7 & $42[30-53]$ & 1.18 & 0.75 & 1.87 \\
\hline Eastern & 1269 & 23.5 & $46[32-61]$ & 1.17 & 0.74 & 1.85 \\
\hline Central & 1717 & 31.8 & $45[31-60]$ & 1.11 & 0.70 & 1.78 \\
\hline Western & 1007 & 18.7 & $40[25-55]$ & 1 & - & - \\
\hline \multicolumn{7}{|l|}{ Type of place of residence } \\
\hline Rural & 4888 & 90.7 & $47[40-55]$ & 1.30 & 0.92 & 1.82 \\
\hline Urban & 503 & 9.3 & $40[26-54]$ & 1 & - & - \\
\hline \multicolumn{7}{|l|}{ Wealth Index } \\
\hline Poorest & 1390 & 25.8 & $49[38-60]$ & $2.53^{* * *}$ & 1.51 & 4.21 \\
\hline Poorer & 1182 & 21.9 & $50[35-66]$ & $2.21^{* *}$ & 1.28 & 3.80 \\
\hline Middle & 1133 & 21.0 & 55 [37-73] & $2.11^{* *}$ & 1.21 & 3.67 \\
\hline Richer & 937 & 17.4 & $41[25-57]$ & $1.90^{*}$ & 1.07 & 3.38 \\
\hline Richest & 748 & 13.9 & 29 [14-45] & 1 & - & - \\
\hline \multicolumn{7}{|l|}{ Ethnicity } \\
\hline Dalit & 958 & 19.8 & $52[34-71]$ & 1.05 & 0.73 & 1.50 \\
\hline Janajati & 1751 & 36.2 & $49[36-60]$ & 1.05 & 0.77 & 1.43 \\
\hline Other (Muslim and Terai other caste) & 410 & 8.5 & $51[23-82]$ & 1.21 & 0.69 & 2.11 \\
\hline Brahmin Chhetri and Newar & 1713 & 35.5 & $38[30-46]$ & 1 & - & - \\
\hline \multicolumn{7}{|l|}{ Religion } \\
\hline Hindu & 4466 & 82.8 & $47[40-55]$ & 1.18 & 0.81 & 1.72 \\
\hline Others & 926 & 17.2 & $42[25-58]$ & 1 & - & - \\
\hline \multicolumn{7}{|l|}{ Highest educational level of mother } \\
\hline No education & 2550 & 47.3 & $55[44-66]$ & $1.55^{*}$ & 1.15 & 2.10 \\
\hline Primary & 1079 & 20.0 & $44[30-58]$ & 1.35 & 0.93 & 1.97 \\
\hline Secondary and higher & 1763 & 32.7 & $36[25-46]$ & 1 & - & - \\
\hline \multicolumn{7}{|l|}{ Highest education level of father } \\
\hline No education & 1243 & 23.2 & 65 [48-83] & $1.71^{* *}$ & 1.26 & 2.32 \\
\hline Primary & 1312 & 24.5 & $51[36-65]$ & 1.32 & 0.97 & 1.79 \\
\hline Secondary and higher & 2801 & 52.3 & $36[28-45]$ & 1 & - & - \\
\hline \multicolumn{7}{|l|}{ Mother occupation } \\
\hline Not working & 1552 & 28.8 & $44[31-59]$ & 0.74 & 0.54 & 1.02 \\
\hline High official work & 147 & 2.7 & 20 [4-40] & 0.38 & 0.12 & 1.20 \\
\hline
\end{tabular}


Table 2 Infant mortality rate (per 1000 live births), 5 year periods preceding the survey and unadjusted Odds Ratio by explanatory variables ( $n=5391$, weighted) (Continued)

\begin{tabular}{|c|c|c|c|c|c|c|}
\hline Sales and service & 315 & 5.8 & 38 [11-66] & 0.59 & 0.32 & 1.09 \\
\hline Skilled manual & 107 & 2.0 & 65 [14-80] & 1.64 & 0.78 & 3.43 \\
\hline Unskilled manual & 103 & 1.9 & 19 [2-49] & 0.62 & 0.23 & 1.70 \\
\hline Agriculture & 3164 & 58.7 & $50[41-58]$ & 1 & - & - \\
\hline \multicolumn{7}{|l|}{ Father occupation } \\
\hline Official type & 873 & 16.6 & $49[31-69]$ & 0.80 & 0.53 & 1.22 \\
\hline Sales, services & 1237 & 23.5 & 33 [23-44] & 0.73 & 0.50 & 1.06 \\
\hline Skilled manual & 951 & 18.1 & $52[33-72]$ & 0.85 & 0.56 & 1.28 \\
\hline Unskilled manual & 833 & 15.9 & $58[40-76]$ & 1.17 & 0.81 & 1.70 \\
\hline Agriculture & 1361 & 25.9 & $45[32-57]$ & 1 & - & - \\
\hline \multicolumn{7}{|l|}{ Sex of the child } \\
\hline Male & 2780 & 51.6 & $46[37-56]$ & 1.06 & 0.83 & 1.37 \\
\hline Female & 2611 & 48.4 & $46[37-56]$ & 1 & - & - \\
\hline \multicolumn{7}{|l|}{ Size of child at birth } \\
\hline Larger than average & 958 & 17.8 & 38 [24-51] & 0.89 & 0.62 & 1.28 \\
\hline Smaller than average & 661 & 12.3 & $42[25-61]$ & 0.91 & 0.61 & 1.36 \\
\hline Very small & 196 & 3.6 & 138 [81-190] & $3.22^{* * *}$ & 2.11 & 4.92 \\
\hline Average & 3569 & 66.3 & $44[36-53]$ & 1 & - & - \\
\hline \multicolumn{7}{|l|}{ Birth rank and birth interval } \\
\hline First birth rank & 1833 & 34.0 & $47[36-59]$ & $1.44^{*}$ & 1.04 & 1.99 \\
\hline $2-3$ birth rank $\&=<2$ years of birth interval & 567 & 10.5 & $72[45-100]$ & $2.07^{* *}$ & 1.37 & 3.12 \\
\hline$>=4$ birth rank \& $>2$ years of birth interval & 895 & 16.6 & $31[18-45]$ & 0.99 & 0.65 & 1.52 \\
\hline$>=4$ birth rank $\&=<2$ years of birth interval & 296 & 5.5 & $81[43-120]$ & $2.37^{* *}$ & 1.46 & 3.85 \\
\hline $2-3$ birth rank and $>2$ years birth interval & 1794 & 33.3 & $39[28-51]$ & 1 & - & - \\
\hline \multicolumn{7}{|l|}{ Age of mother at child birth } \\
\hline$<20$ years & 2941 & 54.6 & $53[43-63]$ & 1.27 & 0.98 & 1.65 \\
\hline 20-35 years & 2450 & 45.4 & 39 [30-48] & 1 & - & - \\
\hline \multicolumn{7}{|l|}{ Antenatal visit } \\
\hline No & 609 & 30.9 & 49 [29-70] & 0.93 & 0.60 & 1.44 \\
\hline Yes & 1363 & 69.1 & 53 [37-68] & 1 & - & - \\
\hline \multicolumn{7}{|l|}{ Use of tobacco } \\
\hline No & 687 & 12.7 & 49 [33-65] & 1.32 & 0.95 & 1.83 \\
\hline Yes & 4704 & 87.3 & $46[38-53]$ & 1 & - & - \\
\hline \multicolumn{7}{|l|}{ Place of delivery } \\
\hline Home & 3402 & 64.1 & $49[40-58]$ & 1.31 & 0.99 & 1.73 \\
\hline Health Facility & 1905 & 35.9 & 38 [28-49] & 1 & - & - \\
\hline \multicolumn{7}{|l|}{ Delivery assistance } \\
\hline By TBA/Others & 3542 & 65.7 & $49[41-58]$ & 1.26 & 0.95 & 1.65 \\
\hline By SBA/Health professional & 1849 & 34.3 & $41[30-52]$ & 1 & - & - \\
\hline
\end{tabular}


Table 2 Infant mortality rate (per 1000 live births), 5 year periods preceding the survey and unadjusted Odds Ratio by explanatory variables ( $n=5391$, weighted) (Continued)

\begin{tabular}{llllll}
\hline Postnatal check of visits & & & & & \\
No & 2221 & 53.8 & $36[26-44]$ & $3.23^{* *}$ & 1.62 \\
Within $24 \mathrm{~h}$ & 1094 & 26.5 & $22[10-33]$ & 1.99 & 0.93 \\
1 day to 45 days & 816 & 19.7 & $11[03-19]$ & 1 & - \\
National total & $\mathbf{5 3 9 1 5 3 9 1}$ & & $\mathbf{4 6}$ & & - \\
\hline
\end{tabular}

${ }^{* * *}=p<0.001 ;{ }^{* *}=p<0.01$ and ${ }^{*}=p<0.05$, uOR unadjusted Odds Ratio, Cl Confidence Interval

Table 3 Multivariate hierarchical logistic regression results by determinants for infant mortality in the 5 years preceding the survey-adjusted Odds Ratio

\begin{tabular}{|c|c|c|c|c|c|c|c|c|c|}
\hline \multirow{3}{*}{$\begin{array}{l}\text { Determinants } \\
\text { Ecological Region }\end{array}$} & \multicolumn{3}{|c|}{ Model I } & \multicolumn{3}{|c|}{ Model II } & \multicolumn{3}{|c|}{ Model III } \\
\hline & \multirow[t]{2}{*}{$\mathrm{aOR}$} & \multicolumn{2}{|c|}{$95 \% \mathrm{Cl}$} & \multirow[t]{2}{*}{$\mathrm{aOR}$} & \multicolumn{2}{|c|}{$95 \% \mathrm{Cl}$} & \multirow[t]{2}{*}{$\mathrm{aOR}$} & \multicolumn{2}{|c|}{$95 \% \mathrm{Cl}$} \\
\hline & & & & & & & & & \\
\hline Mountain & 1.39 & 0.90 & 2.16 & 1.33 & 0.84 & 2.10 & 1.37 & 0.86 & 2.17 \\
\hline Hill & 1.03 & 0.78 & 1.36 & 1.03 & 0.76 & 1.40 & 1.05 & 0.77 & 1.44 \\
\hline Terai & 1 & - & - & 1 & - & - & 1 & - & - \\
\hline \multicolumn{10}{|l|}{ Development Region } \\
\hline Far western & $1.62^{*}$ & 1.02 & 2.57 & 1.58 & 0.99 & 2.53 & 1.49 & 0.92 & 2.40 \\
\hline Mid western & 1.00 & 0.62 & 1.61 & 0.97 & 0.59 & 1.58 & 0.88 & 0.53 & 1.45 \\
\hline Eastern & 1.16 & 0.77 & 1.77 & 1.16 & 0.76 & 1.77 & 1.07 & 0.70 & 1.64 \\
\hline Central & 1.14 & 0.77 & 1.70 & 1.14 & 0.76 & 1.71 & 1.10 & 0.73 & 1.65 \\
\hline Western & 1 & - & - & 1 & - & - & 1 & - & - \\
\hline \multicolumn{10}{|l|}{ Wealth Index } \\
\hline Poorest & & & & 1.55 & 0.92 & 2.61 & 1.56 & 0.91 & 2.68 \\
\hline Poorer & & & & $1.66^{* *}$ & 1.00 & 2.74 & $1.72^{* *}$ & 1.03 & 2.87 \\
\hline Middle & & & & $1.87^{* *}$ & 1.14 & 3.08 & $1.95^{* *}$ & 1.18 & 3.24 \\
\hline Richer & & & & 1.40 & 0.82 & 2.38 & 1.43 & 0.83 & 2.46 \\
\hline Richest & & & & 1 & - & - & 1 & - & - \\
\hline \multicolumn{10}{|l|}{ Size of child at birth } \\
\hline Larger than average & & & & & & & 0.87 & 0.60 & 1.26 \\
\hline Smaller than average & & & & & & & 0.90 & 0.59 & 1.36 \\
\hline Very small & & & & & & & $3.41^{* * *}$ & 2.16 & 5.38 \\
\hline Average & & & & & & & 1 & - & - \\
\hline \multicolumn{10}{|l|}{ Birth rank and birth interval } \\
\hline First birth rank & & & & & & & 1.28 & 0.92 & 1.78 \\
\hline $2-3$ birth rank $\&=<2$ yrs of birth interval & & & & & & & $1.74^{* *}$ & 1.16 & 2.62 \\
\hline$>=4$ birth rank \& $>2$ yrs of birth interval & & & & & & & 0.68 & 0.43 & 1.08 \\
\hline$>=4$ birth rank $\&=<2$ yrs of birth interval & & & & & & & $2.03^{* *}$ & 1.23 & 3.35 \\
\hline $2-3$ birth rank and $>2$ yrs birth interval & & & & & & & 1 & - & - \\
\hline-2 Log likelihood & 2013 & & & 2006 & & & 1950 & & \\
\hline Nagelkerke R Square & 0.005 & & & 0.009 & & & 0.038 & & \\
\hline
\end{tabular}


Negelkerke $R^{2}$ value has increased from model I to model III however its value is low. It suggests that the strength of the association between dependent and independent variable has increased in the successive models.

\section{Discussion}

Analyses of the 2006-2010 Nepal Demographic Health Survey data have revealed consistent relationships between socioeconomic determinants such as wealth of the household and infant mortality. Specifically, middle and poorer classes were vulnerable for infant mortality. Other literature also shows that poor infants are more likely to be exposed to health risks than their better-off peers, and they have less resistance to disease because of under-nutrition and other hazards typical in poor communities. These inequities are compounded by reduced access to preventive and curative interventions. Rich people frequently benefit even from public subsidies for health more than poor people [17]. In addition, there are important practices that are shaped by socioeconomic and environmental influences associated with infant mortality. For example, maternal stress is correlated with premature delivery and lower birth weights both of which are leading causes of infant mortality [18]. Similarly, religious and culturally prescribed and proscribed rules have been practiced in certain ethnic groups may decrease heterozygosity, increase inbreeding and the risk for genetic anomalies leading to increased risk for infant mortality [19]. A recent study in Gaja Strip found that consanguineous marriage was the strongest intermediate factor of infant mortality [20]. Infant mortality decreases with increasing parental education level [21] and better paying occupations which increases household income resulting in higher levels of family consumption and healthier environments. The impact of father's formal education surpassed mother's formal education in explaining infant mortality [22]. Similarly, Nepal Fertility and Family Planning Survey (1986) showed significant effects of access to toilets in lowering infant mortality. Nepali's are experiencing increased access to resources like remittances, toilets and literacy campaigns may reduce the relative impact of these variables on infant mortality. For example, the share of households with access to drinking water (piped to the house) increased from 14 to $22 \%$ from 2004 to 2010 [23]. A reduction in the odds of infant death was observed as the sanitation condition of household increased. Access to a flush toilet was a proxy for household socioeconomic status, which suggests that education and household resources were complementary in lowering the infant mortality [24]. However, in this study, parental education, occupation and environmental-related variables were not included in the analysis model as they were highly correlated with and part of the wealth index.
The majority of infants in this study were from rural areas and infant mortality rates were found to be higher in the rural areas than in urban areas. However, bivariate analysis showed that infant mortality was not statistically significant between rural and urban residence in this period. This indicates the effects of public health program interventions have focused in rural areas. Nepal Health Sector Program II (2010-2015) has targeted to reduce infant mortality at 34 per 1000 live births [25].

Similarly, differences in terms of regional variation were not statistically significant. Likewise, the findings of this analysis showed that sex of the infants did not influence the odds of dying but the literature shows females have lower odds of mortality than males during the first month of life [26-29]. There is evidence from some parts of South Asia that male children receive preferential treatment in terms of better nutrition or health care from their parents [30]. Hence, finding no sex differences in mortality may be due to the large proportion of infants' deaths occurring in the first week of birth, which is the time when the effects of gender differences in mortality are not pronounced. In the other hand, the finding is supported by the increasing trend of the gender parity index in Nepal. That is a positive indication of focused response in addressing gender disparity issues.

All above-mentioned socioeconomic determinants operated through a common set of significant proximate determinants of infant deaths. These determinants were size of babies at birth and birth rank and birth interval. Smaller infant size at birth was found to be one of the strongest determinants of infant mortality. This finding is supported by other literature as well. Low birth weight was a strong predictor of neonatal mortality [31]. Foodavailability also influences child survival by influencing the nutrients available to infants [11]. Tackling the immediate causes of low birth weight should be linked to community-based efforts to deal with the underlying causes of low birth weight, rooted in household and community practices. Hence, further reductions in infant mortality require that maternal nutrition and health issues be addressed. Whilst such programs should be carefully monitored and evaluated, it must be recognized that child survival is reflected throughout the life cycle of women [32]. Furthermore, smoking is also a risk factor that has direct implication in low birth weight. McCormick et al. confirmed the relation that smoking during pregnancy is linked to reduce birth weight [33]. Second hand smoke reduces weight gain and has a negative impact on the health of infants and older children. Nepal Demographic Health Survey, 2011 showed that $5 \%$ of pregnant women and $7 \%$ of breastfeeding women smoke cigarettes. Additionally, $4 \%$ of pregnant women and $6 \%$ of breastfeeding women consume other forms of tobacco. 
Facility-based, population outreach, or home/family/ community based antenatal, natal and postnatal care interventions have been proven to be effective to prevent infant deaths [34-36]. Therefore, the availability and use of public health care services, the utilization of antenatal, postnatal checkups, facility delivery, desired pregnancy, and availability of caesarian section facilities were also important proximate determinants of infant mortality though most of them were not statistically significant in this analysis.

The analysis also found that there was no significant difference between age of the mother and infant mortality though there is a high prevalence of early marriage and early pregnancy in Nepal. In line with this finding, an analysis of the World Fertility Survey data [37] showed that older maternal ages were not detrimental to infant survival. However, there was association between birth rank and birth interval. In fact, maternal fertilityrelated factors have an important influence on infant survival $[26,37,38]$.

The identification of key determinants of infant deaths is important to provide guidance for the development of evidence-based focused interventions. In line with this need, National Health Policy, 2014 and Nepal Health Sector Program (2015-2020) have provisioned equity as a guiding principle of health programs. For this, as Buyana suggests, local government budgeting should be in a two-fold framework that combines both diseasebased health needs and socio-economic needs [39]. Thus, it is important in Nepal to look upstream to address the causes in a holistic and integrated manner for social justice and universal coverage of health.

\section{Limitations}

This paper included live-births, occurred within the 5 years preceding the survey. The associations of infant mortality with factors drawn from statistical analyses might lack a temporal relationship. This is due to the cross-sectional design used in Nepal Demographic Health Survey, 2011, thus limiting causal inference. For example, current poverty is a proxy for past poverty. Finally, the data for the Nepal Demographic Health Survey, 2011 was collected at the individual and household levels. For the present analysis, only crude community level indicators (such as region and urban-rural residence) were used.

\section{Conclusions}

The analysis of NDHS data (2006 to 2010) in this paper demonstrated that socioeconomic determinants are associated with infant mortality in Nepal. Specifically, poorer and middle class people and people who reside in the Mountain ecological region and Far Western development region had high infant mortality. However, determinants like gender and urban/rural residence were found to be statistically insignificant.

These socioeconomic determinants operated through a common set of proximate determinants such as size of babies at birth, birth interval or spacing associated with high infant deaths. Therefore, infant mortality is typically multi-factorial in causality and the cumulative consequences of interactions of social, economic and biological determinants, among others. Hence, findings point to address both socioeconomic and proximate determinants side by side. For this, comprehensive, long-term, equitybased public health interventions and immediate infant care programs are recommended. Moreover, this study recommends an advanced analytical study to explore the independent roles of key determinants of infant mortality in Nepal.

\section{Competing interest}

The authors declare that they have no competing interest.

\section{Authors' contributions}

KBK: Conceptualized the design and overall study. He analyzed and interpreted the data and prepared manuscript. LSL: Guided in conceptualizing the study directed and supported the study and contributed in writing the manuscript and provided inputs. VG: Supported in conceptualizing the study and reviewed the manuscript and provided inputs. LB: Supported in statistical analyses, interpretation of data and reviewed the manuscript and provided inputs. GS: Critically reviewed the manuscript and provided inputs. All authors read and approved the final manuscript.

\section{Authors' information}

KBK: A public health professional having Master Degree in Education from Tribhuvan University in 2002 and Joint Master Degree in Sustainable Regional Health Systems and MPH in 2012 from Vilnius University and currently working in Save the Children Nepal. LSL: A professor emerita at the University of Central Florida and also a managing director of Lieberman Consulting in Florida, USA. She is experienced researcher in biomedical Anthropology, Nutrition and Public Health. VG: A professor at Vilnius University, Lithuania. He is also a coordinator of Regional Health Master Program of European Commission and experienced in research related with economics and Public Health. LB: Student of Master of Business Study in Tribhuvan University, Birendra Multiple Campus, Bharatpur, Nepal and currently working on thesis for master degree. GP: A public health professional having Joint Master Degree in Sustainable Regional Health Systems and MPH in 2012 from Vilnius University and currently working in Save the Children Nepal.

\section{Acknowledgements}

The authors would like to acknowledge the support of the Institute of Public Health of Vilnius University. We also acknowledge Measures DHS for access to the 2011 DHS dataset for Nepal.

\section{Author details}

${ }^{1}$ Save the Children, Kathmandu, Nepal. ${ }^{2}$ Department of Anthropology, University of Central Florida, Orlando, FL 32816-0955, USA. ${ }^{3}$ Faculty of Economics, Vilnius University, Vilnius, Lithuania. ${ }^{4}$ Tribhuvan University, Birendra Multiple Campus, Bharatpur, Nepal.

Received: 21 September 2014 Accepted: 1 October 2015

Published online: 12 October 2015

\section{References}

1. OECD. OECD Factbook 2011-2012: economic, environmental and social statistics. Paris: Organisation for Economic Co-operation and Development; 2011. p. 268.

2. Reidpath $D$, Allotey P. Theory and methods infant mortality rate as an indicator of population health. J Epidemiol Community Health. 2003;57:344-6. 
3. Park K. Park's textbook of preventive and social medicine. India: Bhanot; 2005. p. 414-22.

4. Gubhaju B, Streatfield K, Majumder A. Socioeconomic, demographic and environmental determinants of infant mortality in Nepal. J Biosoc Sci. 1991;23(4):425-35.

5. UNDP. The Millennium Development Goals report 2011. In: United Nations Development Program (UNDP). New York, USA; 2011 a.

6. Bhutta Z, Chopra M, Axelson H, Berman P, Boerma T, Bryce J, et al. Countdown to 2015 decade report (2000-10): taking stock of maternal, newborn, and child survival. Lancet. 2010:375:2031-44.

7. Ministry of Health and Population, New ERA and ICF International. Nepal Demographic and Health Survey 2011. In. Kathmandu, Nepal: Ministry of Health and Population, New ERA, and ICF International, Calverton, Maryland.; 2012.

8. Word Bank Nepal. Providing Essential Health Services to Nepal's Poorest and Most Excluded. In: Kathmandu Nepal: World Bank ;2010.

9. HSRSP. Equity analysis to resource allocation to districts, health sector reform support programme. HSRSP: Kathmandu; 2007.

10. Sharma RK. Demography and population problems. New Delhi: Atlantic publishers and distributors private limited; 2007.

11. Mosley WH, Chen LC. An analytical framework for the study of child survival in developing countries. Popul Dev Rev. 1984;10:25-45.

12. Measure Evaluation, ICF. Demographic and Health Surveys. In: Calverton, MD 20705 USA: Measure DHS; 2011.

13. Rutstein SO, Johnson K. The DHS Wealth Index. DHS comparative reports no. 6. Calverton, Maryland: ORC Macro; 2004

14. Howe LD, Hargreaves JR, Huttly SR. Issues in the construction of wealth indices for the measurement of socio-economic position in low-income countries. Emergency Themes Epidemiology 2008, 5(3). doi: 10.1186/17427622-5-3.

15. Titaley CR, Dibley MJ, Agho K, Roberts CL, Hall J. Determinants of neonatal mortality in Indonesia. BMC Public Health 2008, 8(232). doi: 10.1186/14712458-8-232

16. Levy PS, Lemeshow S. Sampling of populations. New York: Wiley; 2011

17. Victora CG, Wagstaff A, Schellenberg JA, Gwatkin D, Claeson M, Habicht JP. Applying an equity lens to child health and mortality: more of the same is not enough. Lancet. 2003;362(9387):233-41.

18. Loafman MT, Zhang F, Cherella CE. Addressing psychosocial determinants of poor birth outcomes:enhanced screening in family medicine obstetrics. Am J Clin Med. 2009;6(2):58-64.

19. Chantia A. Effects of inbreeding on health among Dhankut -An Endogamous Group of Bahraich, Uttar Pradesh. Anthropol. 2008;10(3):219-23.

20. Abuqamar M, Coomans D, Louckx F. The impact of intermediate factors on socioeconomic differences and infant mortality in the Gaza Strip. Int J Med Med Sci. 2011;3(4):92-9.

21. Shakya K, McMurray C. Neonatal mortality and maternal health care in Nepal: searching for patterns of association. J Biosoc Sci. 2001;33(1):87-105.

22. G̈̈rsoy A. Forum: parental education and child mortality. Health Transit Rev. 1994;4:183-229.

23. CBS. Nepal living standards survey. Kathmandu, Nepal: Central Bureau of Statistics; 2010-11.

24. Pant PD. Effect of education and household characteristics on infant and child mortality in urban Nepal. J Biosoc Sci. 1991;23(04):437-43.

25. Ministry of Health and Population. Nepal health sector programme implementaion plan- II. Kathmandu: Ministry of Health and Population; 2010.

26. Hobcraft JN, McDonald JW, Rutstein SO. Demographic determinants of infant and early child mortality: a comparative analysis. J Demogr. 1985;39(3):363-85

27. Koenig MA, D'Souza S. Sex differences in childhood mortality in rural Bangladesh. Soc Sci Med. 1986;22(1):15-22.

28. Green $M$. The male predominance in the incidence of infectious diseases in children: a postulated explanation for disparities in the literature. Int J Epidemiol. 1992;21(2):381-6.

29. Alonso V, Fuster V, Luna F. Causes of neonatal mortality in Spain (1975-98): influence of sex, rural-urban residence and age at death. J Biosoc Sci. 2006;38(4):537-51.

30. Muhuri PK, Preston SH. Effects of family composition on mortality differentials by sex among children in Matlab, Bangladesh. Popul Dev Rev. 1991:17:415-34
31. Lawn JE, Cousens S, Zupan J. 4 million neonatal deaths: when? where? why? Lancet. 2005;365:891-900.

32. Shrimpton R. Reducing childhood mortality in poor countries, preventing low birth weight and reducing child mortality. Trans R Soc Trop Med Hyg. 2003;97:39-42

33. McCormick MC, Brooks-Gunn J, Shorter T, Holmes JH, Wallace CY, Heagarty MC Factors associated with smoking in low-income pregnant women: relationship to birth weight, stressful life events, social support, health behaviors and mental distress. J Clin Epidemiol. 1990;43(5):441-8.

34. Martines J, Paul V, Bhutta Z, Koblinsky M, Soucat A, Walker N, et al. Neonatal survival: a call for action. Lancet. 2005;365(9465):1189-97.

35. Darmstadt GL, Bhutta ZA, Cousens S, Adam T, Walker N, de Bernis L. Evidence-based, cost-effective interventions: how many newborn babies can we save? Lancet. 2005;365:977-88.

36. Sines E, Syed U, Wall S, Worley H. Postnatal Care: A Critical Opportunity to Save Mothers and Newborns. Policy Perspective on Newborn Health-Saving Newborn Lives 2007:1-8. http://www.prb.org/pdf07/snl_pncbrieffinal.pdf.

37. Martin LG, Trussell J, Salvail FR, Shah NM. Co-variates of child mortality in the Philippines, Indonesia, and Pakistan: an analysis based on hazard models. J Demogr. 1983;37(3):417-32.

38. Cleland JG, Sathar ZA. The effect of birth spacing on childhood mortality in Pakistan. J Demogr. 1984;38(3):401-18.

39. Buyana K. Delivering on a gendered definition of health needs in local government budgeting: experiences and concepts. Cavendish University, Kampala, Uganda: African Health Science; 2009.

\section{Submit your next manuscript to BioMed Central and take full advantage of:}

- Convenient online submission

- Thorough peer review

- No space constraints or color figure charges

- Immediate publication on acceptance

- Inclusion in PubMed, CAS, Scopus and Google Scholar

- Research which is freely available for redistribution 